\title{
Comparison of accuracy between dental and skeletal age in the estimation of chronological age of Down syndrome individuals
}

\author{
Leila Abou Hala ${ }^{a}$, Mari Eli Leonelli de Moraes ${ }^{b}$, Maria Fernanda Lima Villaça-Carvalho ${ }^{c}$, \\ Sérgio Lúcio Pereira de Castro Lopes ${ }^{\mathrm{d}}$, Thiago de Oliveira Gamba ${ }^{\mathrm{e}, *}$ \\ ${ }^{a}$ ICT - Institute of Science and Technology - School of Dentistry - UNESP, São José dos Campos, São Paulo, Brazil \\ ${ }^{\mathrm{b}}$ Discipline of Radiology, Department of Diagnostic and Surgery, ICT - Institute of Science and Technology - School of Dentistry - UNESP, São José dos Campos, \\ São Paulo, Brazil \\ ${ }^{\mathrm{c}}$ Department of Diagnostic and Surgery, Institute of Science and Technology - School of Dentistry - UNESP, São José dos Campos, São Paulo, Brazil \\ ${ }^{\mathrm{d}}$ Discipline of Radiology, Department of Diagnostic and Surgery, São José dos Campos, São Paulo, Brazil

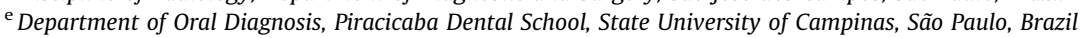

\section{A R T I C L E I N F O}

\section{Article history:}

Received 8 June 2015

Received in revised form 4 May 2016

Accepted 16 June 2016

Available online 23 June 2016

\section{Keywords:}

Down syndrome

Bone development

Tooth mineralization

Age determination by teeth

Forensic anthropology population data

\begin{abstract}
A B S T R A C T
This study aimed to evaluate the accuracy of dental age (DA) and skeletal age (SA) methods in order to estimate chronological age (CA) in individuals with Down syndrome (DS), contributing to the Forensic Dentistry and making the identification of these individuals age possible. For this, 278 images of individuals were selected and divided in 2 groups: 216 non-DS patients and 62 with DS. At first, DA was evaluated by Nolla method, on panoramic radiographs, followed by SA, evaluated by Greulich and Pyle method. The linear correlation coefficient of Pearson was used for the analysis of concordance between the methods. Paired $t$-test with confidence interval was used to evaluate the accuracy and Bland and Altman method was applied to estimate limits of concordance. Complementary to this first analysis, descriptive statistics and ANOVA test were applied for comparison among chronological age (CA), dental age (DA) and skeletal age (SA), with a significance level of $95 \%(p \geq 0.05)$, ordering to observe the differences among them. DA, estimated by Nolla, is underestimated in both, DS and non-DS individuals, and it is more notable in DS individuals. SA estimated by Greulich and Pyle method is overestimated, except for non-DS males. The range of variance is greater in SA and DS than DA and non-DS individuals, respectively. A greater accordance was found for $\mathrm{DA} \times \mathrm{CA}$ if compared to $\mathrm{SA} \times \mathrm{CA}$, indicating that $\mathrm{DA}$, estimated by Nolla method, is more accurate than SA, evaluated by Greulich and Pyle method, for estimating CA of both, DS and non-DS individuals. However, neither method seems to be precise and more caution is required for age estimation in DS individuals.
\end{abstract}

(C) 2016 Elsevier Ireland Ltd. All rights reserved.

\section{Introduction}

Many factors may influence the estimation of chronological age (CA), especially in children with Down syndrome (DS). Moreover, without age definition, the difficulty in the identification process becomes evident and, consequently, adoption, criminal and legal responsibility and other legal processes are harmed, since age is decisive for these cases. Determining CA of children and their stage of physiological maturity is particularly important in areas such as pediatrics, orthodontics and orthopedics, as well as forensic and

\footnotetext{
* Corresponding author at: Department of Oral Radiology, School of Dentistry, UNICAMP, Limeira Avenue, 901, PO Box 52, Piracicaba, SP, Brazil. Tel.: +55 1921065327.

E-mail address: thiagodeo.gamba@gmail.com (T.d.O. Gamba).
}

anthropological issues [1-4]. Genetic, hormonal, racial, climatic, environmental, socioeconomic and nutritional factors are known to influence the maturation process, leading, in most cases, to an incompatibility between the CA of individuals and their physiological development [4-9].

The number of children placed in orphanages or institutions for minors, has increased over the years. Among the reasons are illnesses, physical abnormalities or deformities, poor family structure, financial challenges and others such as criminal and legal responsibility, child pornography, illegal immigration, subadult delinquency and juvenile work and because many other social events such as birth certificate, marriage, job, army recruitment, and retirement [8,10-13].

Gibelli et al. [13] reported a case concerning age estimation for a newly adopted child from Cambodia; previous clinical documentation revealed information suggesting possible malnutrition, 
which was verified by the observation of general bone dealignment and dental structures. This example shows the importance of a rigorous forensic evaluation of adopted children from other countries in order to verify the possible environmental modification of physiological growth, even where it seems not necessary, and represents a caveat for clinical and social personnel dealing with adoption procedures.

These children, in most cases, are deprived of personal documents, necessary to prove their identity, including age and name. This could impair decision making toward health care and hamper the adoption process $[10,14]$. CA of an individual involves social, legal and criminal implications and thus its accurate estimation is crucial [1].

Although some methods may be tempting because novel and bearing low error rates, for forensic purposes it is safer using, when possible, the more traditional and standardized methods, possibly tested on different populations and apply the correct population reference for the individual one that is being studied.

Furthermore, it is necessary to point out that age estimation concerns biology, where variability is the rule; even considering population data, every individual may show different aging patterns. A correct age estimation must consider this unavoidable limit, in order to define with precision the limits of results provided [4]. Judiciary, at times, resorts to forensic dentistry to estimate CA of individuals involved in a lawsuit as a complementary approach toward their identification. Among the factors used to estimate CA of an individual are sexual maturity (secondary sexual characteristics), dental age (DA), skeletal age (SA) and morphological age (weight/height) [14-16]. Some studies were carried out with the aim to verify the accuracy among the methods used to estimate the CA of an individual [17-20].

Frequently, tooth mineralization, through DA, and skeletal maturation of the ossification centers of the hand and wrist, through SA, are among the parameters used to estimate the CA and degree of development and growth of an individual $[1,8,12]$. Tooth mineralization is considered an efficient and accurate variable toward sex differentiation since teeth are less susceptible to nutritional, hormonal and pathological alterations, especially in children [10]. Many are the methods used to estimate CA; however, little has been reported on forensic dentistry toward the identification and age estimation of an individual, a condition deemed crucial for the adoption and legal process [10,15,21,22].

The difficulty increases when these individuals have diseases or syndrome and other conditions which may modify the normal development. DS is the most common congenital mental disability $[7,23]$ and it occurs in approximately one in every 700 births. There are more than 5.8 million individuals in the world with DS [3]. These individuals present signs and symptoms that characterize a delay in the development of the motor and mental functions of its carriers, entailing mental and general alterations that may lead to different results if the same criterion is used to evaluate their CA [24].

Taking into consideration the previous data, the aim of this study was to compare which of the two developmental parameters (DA or $\mathrm{SA}$ ) is more accurate to estimate the CA of individuals with DS.

\section{Materials and methods}

This study was authorized by the Local Research Ethics Committee of ICT UNESP, Faculty of Dentistry, São José dos Campos ( $\mathrm{N}^{\circ}$ 004/2011 - PH/CEP) according to National Consul of Health. The sample included panoramic and hand-wrist radiographs of 278 patients, aged between 3 and 17 years: 62 DS (35 males and 27 females) and 216 non-DS (100 males and 116 females) as the Control Group. Radiographs were provided by the Department of Oral Radiology, São Paulo State University,
“Júlio de Mesquita Filho". Images were attained with a Rotograph ${ }^{\circledR}$ imaging system (Villa Sistemi, Medicali - Buccinasco, MI, Italy). All the exams had the approval from parents or guardians and they were done during the treatment of these patients in the University.

Inclusion criteria included age between 3 and 17 years and both exams (panoramic and hand-wrist radiographs) were taken at the same day. The images were evaluated by a previously calibrated dentist, who is a specialist in oral radiology analysis. The sample was evaluated without prior knowledge of the examiner toward the chronological age of the individuals. Both, panoramic and hand and wrist radiographs, were evaluated separately to avoid bias regarding the age estimation. Two readings of each radiographic examination were performed at least 6 weeks apart. An average was calculated for the readings.

Patients were initially divided into 2 groups: Control Group (individuals without Down syndrome) and DS group (individuals with Down syndrome). Then, these groups were subdivided according to chronological age in months: G1: approximately 80-120 months; G2: approximately 121-160 months; and G3: approximately 161-204 months. In addition, patients were further subdivided into 3 groups according to gender: MG (Masculine Group); FG (Feminine Group); GG (Gathered Group).

\subsection{Dental age (DA) - chronological analysis of the tooth mineralization}

Tooth mineralization of permanent teeth was evaluated using DA method, described by Nolla [25] (Figs. 1 and 2), using a schematic table (Tables 1 and 2), showing the 10 stages of the tooth development. Due to the numerous missing teeth, which commonly occur in individuals with Down syndrome, the method proposed by Nolla allowed adaptations to the methodology, allowing the evaluation with lower number of teeth, since the method proposed by Demirjian requires the presence of all teeth. This analysis involved the second molar on the left side of the mandible. In cases where the target tooth was missing, the corresponding contra-lateral tooth was evaluated. When there was doubt between two stages of the tooth mineralization, the lower was recorded.

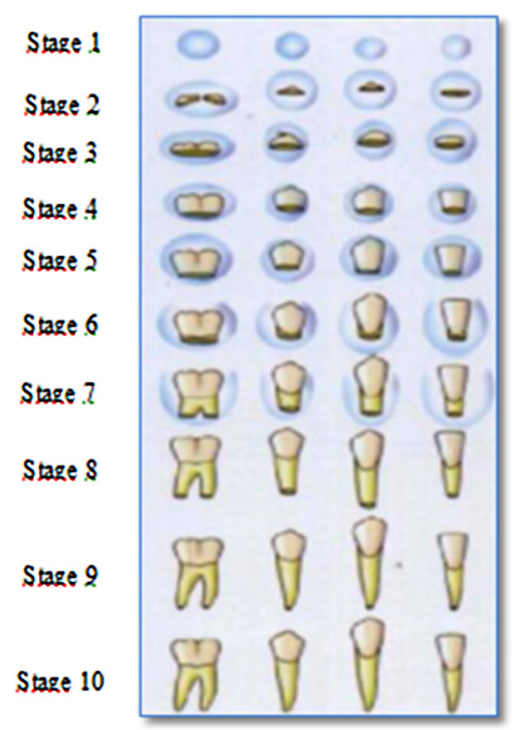

Fig. 1. Ten stages of Nolla [25], used as a parameter for evaluation of tooth development compared with the image in the panoramic radiograph of teeth: where 1 = presence of crypt; 2 = initial calcification; 3 = a third complete crown; 4 = two-thirds complete crown; $5=$ almost complete crown; $6=$ complete crown; $7=\mathrm{a}$ third complete of root; $8=$ two thirds complete of root; $9=$ almost complete root and open apex; $10=$ complete root and apex. 

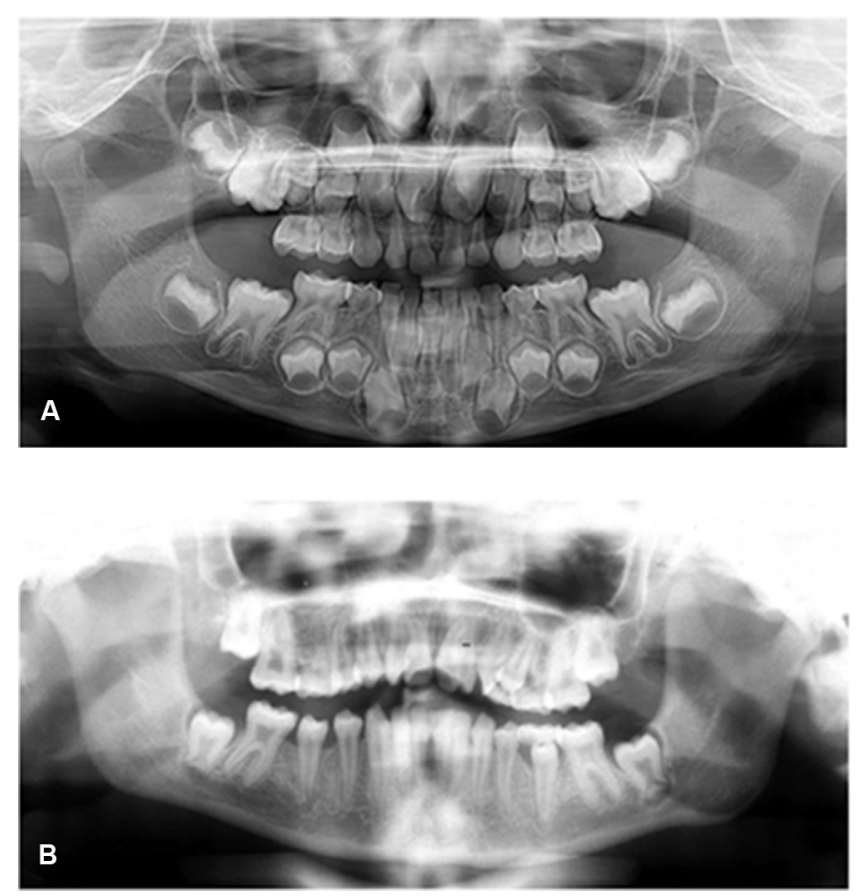

Fig. 2. Example of panoramic radiography used to evaluate dental age by Nolla method [25]. (A) Individuals non-Down syndrome and (B) individuals with Down syndrome presenting various dental abnormalities.
2.2. Skeletal age (SA) - analysis of skeletal maturation using hand and wrist ossification centers

This analysis was based on standardized radiographic ossification parameters described in the Greulich and Pyle method [26], which is presented in Radiographic Atlas of Skeletal Development of the Hand and Wrist (Fig. 3). This atlas illustrates the developmental stages of the hand and wrist bones. SA of individuals was determined according to the Atlas, in which age is defined by month (Fig. 4).

\subsection{Statistical analysis}

Data were statistically analyzed as follows: the linear correlation coefficient of Pearson was used to verify concordance between the methods and the paired $t$-Student test to evaluate the accuracy and confidence of interval of the techniques used. Bland-Altman method was used to estimate the limits of concordance between the groups.

For complementary statistical analysis, we tried to work with three divisions of the sample for both Control Group (CG) and for Down syndrome Individuals Group (DSG): Feminine Group (FG); Masculine Group (MG); and Gathered Group (GG) - grouped sample group (both genders). Initially, descriptive statistics exhibition of absolute and relative numbers of the sample was performed. Complementary to this first analysis, ANOVA test was applied, for comparison among chronological age (CA), dental age

Table 1

Amounts allocated to the development of permanent teeth in boys (Nolla [25]).

\begin{tabular}{|c|c|c|c|c|c|c|c|c|c|c|c|c|c|c|c|c|}
\hline \multirow{3}{*}{$\begin{array}{l}\text { Dental age } \\
\text { Years }\end{array}$} & \multicolumn{16}{|c|}{ Permanent teeth - boys } \\
\hline & \multicolumn{8}{|c|}{ Inferiores teeth } & \multicolumn{8}{|c|}{ Superior teeth } \\
\hline & CI & LI & C & $1^{\circ} \mathrm{PM}$ & $2^{\circ} \mathrm{PM}$ & $1^{\circ} \mathrm{M}$ & $2^{\circ} \mathrm{M}$ & $3^{\circ} \mathrm{M}$ & $\mathrm{CI}$ & LI & C & $1^{\circ} \mathrm{PM}$ & $2^{\circ} \mathrm{PM}$ & $1^{\circ} \mathrm{M}$ & $2^{\circ} \mathrm{M}$ & $3^{\circ} \mathrm{M}$ \\
\hline 3 & 5.3 & 4.7 & 3.4 & 2.9 & 1.7 & 5.0 & 1.6 & & 4.3 & 3.7 & 3.3 & 2.6 & 2.0 & 4.5 & 1.8 & \\
\hline 4 & 6.6 & 6.0 & 4.4 & 3.9 & 2.8 & 6.2 & 2.8 & & 5.4 & 4.8 & 4.3 & 3.6 & 3.0 & 5.7 & 2.8 & \\
\hline 5 & 7.6 & 7.2 & 5.4 & 4.9 & 3.8 & 7.3 & 3.9 & & 6.5 & 5.8 & 5.3 & 4.6 & 4.0 & 6.9 & 3.8 & \\
\hline 6 & 8.5 & 8.1 & 6.3 & 5.8 & 4.8 & 8.1 & 5.0 & & 7.4 & 6.7 & 6.2 & 5.6 & 4.9 & 7.9 & 4.7 & \\
\hline 7 & 9.3 & 8.9 & 7.2 & 6.7 & 5.7 & 8.7 & 5.9 & 1.8 & 8.3 & 7.6 & 7.0 & 6.5 & 5.8 & 8.7 & 5.6 & \\
\hline 8 & 9.8 & 9.5 & 8.0 & 7.5 & 6.6 & 9.3 & 6.7 & 2.1 & 9.0 & 8.4 & 7.8 & 7.3 & 6.6 & 9.3 & 6.5 & 2.1 \\
\hline 9 & 10.0 & 9.9 & 8.7 & 8.3 & 7.4 & 9.7 & 7.4 & 2.3 & 9.6 & 9.1 & 8.5 & 8.1 & 7.4 & 9.7 & 7.2 & 2.4 \\
\hline 10 & & 10.0 & 9.2 & 8.9 & 8.1 & 10.0 & 8.1 & 3.2 & 10.0 & 9.6 & 9.1 & 8.7 & 8.1 & 10.0 & 7.9 & 3.2 \\
\hline 11 & & & 9.7 & 9.4 & 8.6 & & 8.6 & 3.7 & & 10.0 & 9.5 & 9.3 & 8.7 & & 8.5 & 4.3 \\
\hline 12 & & & 10.0 & 9.7 & 9.1 & & 9.1 & 4.7 & & & 9.8 & 9.7 & 9.3 & & 9.0 & 5.4 \\
\hline 13 & & & & 10.0 & 9.4 & & 9.5 & 5.8 & & & 10.0 & 10.0 & 9.7 & & 9.5 & 6.2 \\
\hline 14 & & & & & 9.7 & & 9.7 & 6.5 & & & & & 10.0 & & 9.7 & 6.8 \\
\hline 15 & & & & & 10.0 & & 9.8 & 6.9 & & & & & & & 9.8 & 7.3 \\
\hline 16 & & & & & & & 10.0 & 7.5 & & & & & & & 10.0 & 8.0 \\
\hline 17 & & & & & & & & 8.0 & & & & & & & & 8.7 \\
\hline
\end{tabular}

Table 2

Amounts allocated to the development of permanent teeth in girls (Nolla [25]).

\begin{tabular}{|c|c|c|c|c|c|c|c|c|c|c|c|c|c|c|c|c|}
\hline \multirow{3}{*}{$\begin{array}{l}\text { Dental age } \\
\text { Years }\end{array}$} & \multicolumn{16}{|c|}{ Permanent teeth - girls } \\
\hline & \multicolumn{8}{|c|}{ Inferiores teeth } & \multicolumn{8}{|c|}{ Superior teeth } \\
\hline & $\mathrm{CI}$ & LI & $\mathrm{C}$ & $1^{\circ} \mathrm{PM}$ & $2^{\circ} \mathrm{PM}$ & $1^{\circ} \mathrm{M}$ & $2^{\circ} \mathrm{M}$ & $3^{\circ} \mathrm{M}$ & $\mathrm{CI}$ & LI & $\mathrm{C}$ & $1^{\circ} \mathrm{PM}$ & $2^{\circ} \mathrm{PM}$ & $1^{\circ} \mathrm{M}$ & $2^{\circ} \mathrm{M}$ & $3^{\circ} \mathrm{M}$ \\
\hline 3 & 5.2 & 4.5 & 3.2 & 2.6 & 1.1 & 5.0 & 0.7 & & 4.3 & 3.4 & 3.0 & 2.0 & 1.0 & 4.2 & 1.0 & \\
\hline 4 & 6.5 & 5.7 & 4.2 & 3.5 & 2.2 & 6.2 & 2.0 & & 5.4 & 4.5 & 3.9 & 3.0 & 2.0 & 5.3 & 2.0 & \\
\hline 5 & 7.5 & 6.8 & 5.1 & 4.4 & 3.3 & 7.0 & 3.0 & & 6.4 & 5.5 & 4.8 & 4.0 & 3.0 & 6.4 & 3.0 & \\
\hline 6 & 8.2 & 7.7 & 5.9 & 5.2 & 4.3 & 7.7 & 4.0 & & 7.3 & 6.4 & 5.6 & 4.9 & 4.0 & 7.4 & 4.0 & \\
\hline 7 & 8.8 & 8.5 & 6.7 & 6.0 & 5.3 & 8.4 & 5.0 & 0.8 & 8.2 & 7.2 & 6.3 & 5.7 & 4.9 & 8.2 & 5.0 & \\
\hline 8 & 9.3 & 9.1 & 7.1 & 6.8 & 6.2 & 9.0 & 5.9 & 1.4 & 8.8 & 8.0 & 7.0 & 6.5 & 5.8 & 8.9 & 5.8 & 1.0 \\
\hline 9 & 9.7 & 9.5 & 8.0 & 7.5 & 7.0 & 9.5 & 6.7 & 1.8 & 9.4 & 8.7 & 7.7 & 7.2 & 6.6 & 9.4 & 6.5 & 1.8 \\
\hline 10 & 10.0 & 9.8 & 8.6 & 8.2 & 7.7 & 9.8 & 7.4 & 2.0 & 9.7 & 9.3 & 8.4 & 7.9 & 7.3 & 9.7 & 7.2 & 2.3 \\
\hline 11 & & & 9.1 & 8.8 & 8.3 & 9.9 & 7.9 & 2.7 & 9.95 & 9.7 & 8.8 & 8.6 & 8.0 & 9.8 & 7.8 & 3.0 \\
\hline 12 & & & 9.6 & 9.4 & 8.9 & & 8.4 & 3.5 & & 9.95 & 9.2 & 9.2 & 8.7 & & 8.3 & 4.0 \\
\hline 13 & & & 9.8 & 9.7 & 9.4 & & 8.9 & 4.5 & & & 9.6 & 9.6 & 9.3 & & 8.8 & 4.9 \\
\hline 14 & & & & 10.0 & 9.7 & & 9.3 & 5.3 & & & 9.8 & 9.8 & 9.6 & & 9.3 & 5.9 \\
\hline 15 & & & & & 10.0 & & 9.7 & 6.2 & & & 9.9 & 9.9 & 9.9 & & 9.6 & 6.6 \\
\hline 16 & & & & & & & 10.0 & 7.3 & & & & & & & 10.0 & 7.7 \\
\hline 17 & & & & & & & & 7.6 & & & & & & & & 8.0 \\
\hline
\end{tabular}




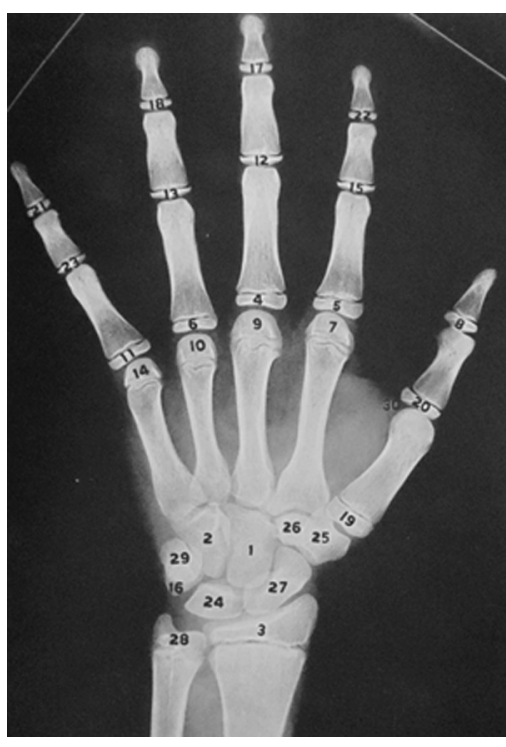

Fig. 3. The 30 bones that make up the hand-wrist radiographs, according Greulich and Pyle atlas [26].
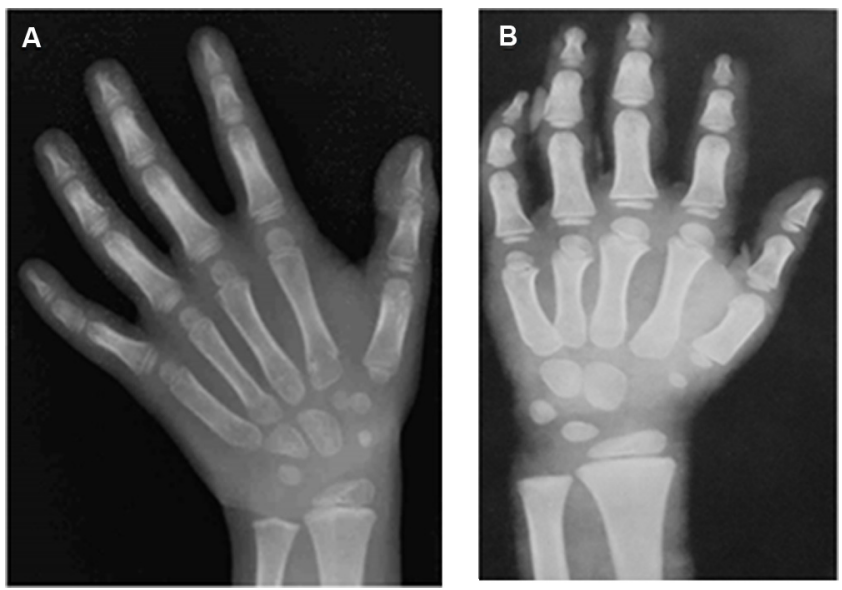

Fig. 4. Example of carpal radiography used to evaluate bone age with corresponding standard Greulich and Pyle Atlas [26]. (A) Individual with Down syndrome and (B) individual non-Down syndrome, according standard Greulich and Pyle Atlas.

(DA) and skeletal age (SA), with a significance level of $95 \%$, in order to observe the differences among them.

\section{Results}

\subsection{Sample}

Table 3 shows the mean and standard deviation of CA, DA and SA of both groups (DS and non-DS). Table 4 shows the number $(n)$

Table 3

DS and non-DS individuals. Descriptive statistical analysis of values: chronological age (CA), dental age (DA), skeletal age (SA) - age (months) according to gender.

\begin{tabular}{|c|c|c|c|c|c|c|c|}
\hline \multirow[t]{2}{*}{ Gender } & \multirow[t]{2}{*}{ Variables } & \multicolumn{3}{|l|}{ DS } & \multicolumn{3}{|l|}{ Non-DS } \\
\hline & & $n$ & Mean & SD & $n$ & Mean & SD \\
\hline \multirow[t]{3}{*}{ Female } & CA & 27 & 122.0 & 41.2 & 116129.6 & 129.6 & 34.1 \\
\hline & DA & 27 & 115.3 & 46.1 & 116 & 125.9 & 34.4 \\
\hline & SA & 27 & 128.5 & 55.4 & 116 & 129.6 & 41.2 \\
\hline \multirow[t]{3}{*}{ Male } & CA & 35 & 124.2 & 42.4 & 100 & 132.2 & 33.8 \\
\hline & DA & 35 & 118.8 & 47.7 & 100 & 130.6 & 36.1 \\
\hline & SA & 35 & 129.8 & 61.2 & 100 & 122.9 & 36.9 \\
\hline
\end{tabular}

$\mathrm{SD}$, standard deviation; $n$, number of individuals; CA, chronological age; DA, dental age; SA, skeletal age.
Table 4

Dental (DA) and skeletal age (SA) compared to chronological age (CA). Values indicate number $(n)$ and percentage of DS and non-DS individuals, considering both genders.

\begin{tabular}{|c|c|c|c|c|c|c|c|c|c|}
\hline \multirow[t]{3}{*}{ Gender } & \multirow[t]{3}{*}{ Group } & \multicolumn{4}{|c|}{$\mathrm{DA} \times \mathrm{CA}$} & \multicolumn{4}{|c|}{$\mathrm{SA} \times \mathrm{CA}$} \\
\hline & & \multicolumn{2}{|c|}{$\mathrm{DA} \geq \mathrm{CA}$} & \multicolumn{2}{|c|}{$\mathrm{DA}<\mathrm{CA}$} & \multicolumn{2}{|c|}{$\mathrm{SA} \geq \mathrm{CA}$} & \multicolumn{2}{|c|}{$\mathrm{SA}<\mathrm{CA}$} \\
\hline & & $n$ & $\%$ & $n$ & $\%$ & $n$ & $\%$ & $n$ & $\%$ \\
\hline \multirow[t]{2}{*}{ Female } & Non-DS & 43 & 37.07 & 73 & 62.93 & 60 & 51.72 & 56 & 48.28 \\
\hline & DS & 9 & 33.33 & 18 & 66.67 & 19 & 70.37 & 8 & 29.63 \\
\hline \multirow[t]{2}{*}{ Male } & Non-DS & 44 & 44.00 & 56 & 56.00 & 32 & 32.00 & 68 & 68.00 \\
\hline & DS & 12 & 34.28 & 23 & 65.72 & 18 & 51.43 & 17 & 48.57 \\
\hline
\end{tabular}

and percentage (\%) of DS and non-DS individuals and their relations between $\mathrm{DA} \times \mathrm{CA}$ and $\mathrm{SA} \times \mathrm{CA}$ considering the delay or advance of ages for both genders. Figs. 5 and 6 show the plot of relation between $\mathrm{DA} \times \mathrm{CA}$ and $\mathrm{SA} \times \mathrm{CA}$.

Fig. 7 shows the concordance between DA and SA when compared to CA. Table 5 shows the linear correlation coefficient of Pearson used to verify concordance between the methods.

Table 6 shows Bland-Altman method to estimate the limits of concordance between $\mathrm{CA} \times \mathrm{DA}$ and $\mathrm{CA} \times \mathrm{SA}$ in Tables 5 and 6 , with numbers and percentages of individuals, between differences $\mathrm{DA} \times \mathrm{CA}$ and $\mathrm{SA} \times \mathrm{CA}$, considered equal (no differences), light (differences less than 12 months), moderate (between 12 and 24 months) or remarkable (bigger than 24 months).

\subsubsection{Control}

3.1.1.1. Gathered Group. GG of the Control Group was composed by 216 patients, 100 from FG and 116 from MG.

In Table 7 and Fig. 8, it is possible to observe the average of CA, DA and SA, where it was found that DA is closer to CA. In the ANOVA test for comparison among CA, DA and SA, it was found statistically significant difference between CA and SA $(p<0.01)$ and no difference among CA and DA and SA for Group 1. There was no statistically significant difference among CA, DA and SA for Groups 2 and 3.

3.1.1.2. Feminine Group. FG of Control Group was composed by 100 patients.

In Table 8 and Fig. 10, it is possible to observe the average of CA, DA and SA, where it was found that DA is closer to the CA. In the ANOVA for comparison among CA, DA and SA, it was found statistically significant difference between CA and SA $(p<0.05)$, and DA and SA $(p<0.01)$ and no difference between CA and DA for Group 3. There was no statistically significant difference among CA, DA and SA for Groups 1 and 2.

\subsubsection{Masculine Group. MG of the Control Group was composed} by 116 patients.

In Table 9 and Fig. 12, it is possible to observe the average of CA, DA and SA, where it was found that DA is closer to CA. In the ANOVA for comparison between CA, DA and SA, it was found statistically significant difference between CA and SA $(p<0.05)$ and DA and SA $(p<0.05)$ and no difference between CA and DA for Group 2. There was no statistically significant difference among CA, DA and SA for Groups 1 and 3

\subsubsection{Down syndrome individuals}

3.1.2.1. Gathered Group. GG of Down syndrome individuals was composed by 62 patients, 27 from FG and 35 from MG.

In Table 7 and Fig. 9, it is possible to observe the average of CA, DA and SA, where it was found that DA is closer to CA. In the ANOVA test for comparison among CA, DA and SA, it was found 
A

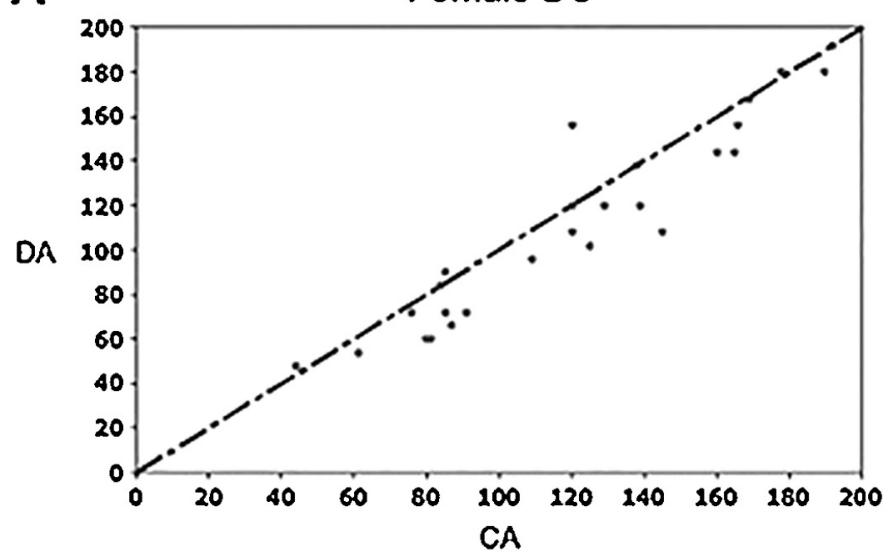

C

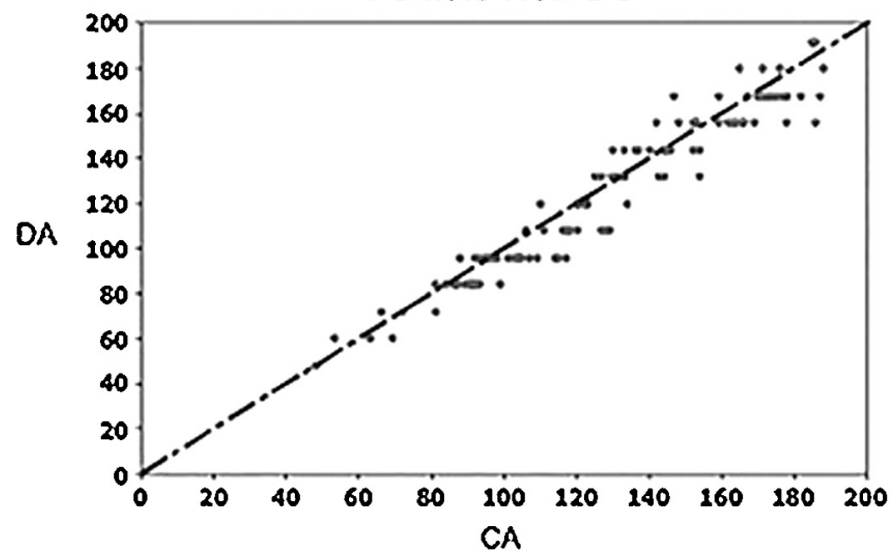

B

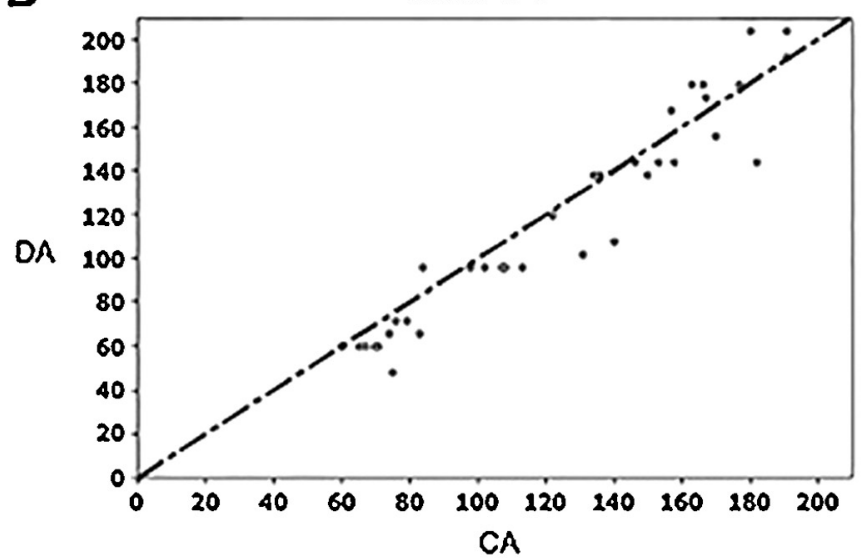

D

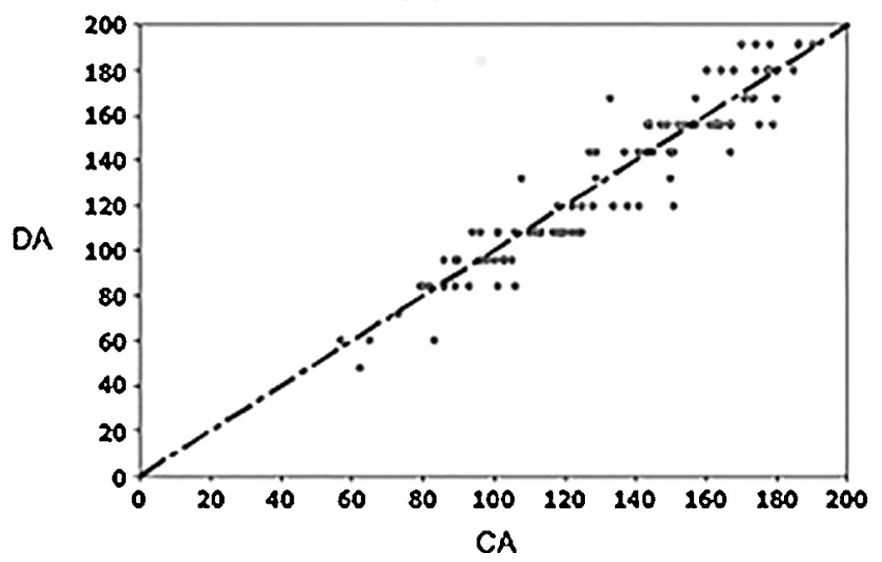

Fig. 5. Charts representing the difference between $D A \times C A$ in each group.

statistically significant difference between CA and SA $(p<0.01)$ and DA and SA $(p<0.01)$ and no difference between CA and DA for Group 2. There was no statistically significant difference among CA, DA and SA for Groups 1 and 3.

3.1.2.2. Feminine Group. FG of Down syndrome individuals was composed by 27 patients.

In Table 8 and Fig. 11, it is possible to observe the average of CA, DA and SA, where it was found that DA is closer to CA. In the ANOVA test for comparison among CA, DA and SA, it was found that there was no difference for Groups 1, 2 and 3.

3.1.2.3. Masculine Group. MG of Down syndrome individuals was composed by 35 patients.

In Table 9 and Fig. 13, we can observe the average of CA, DA and SA, where it was found that DA is closer to CA. In the ANOVA test for comparison among CA, DA and SA, it was found statistically significant difference between CA and SA $(p<0.01)$, and DA and SA $(p<0.01)$ and no difference between CA and DA for Group 2. There was no statistically significant difference between CA, DA and SA in Groups 1 and 3.

\section{Discussion}

In the globalized word that we live in, administrating records of CA do not always correspond to biological reality of an individual. Since age has social and penal implications, some degree of accuracy is required in its determination. Nevertheless, the number of cases in which an individual's exact CA is unknown has increased in recent years, probably as a result of uncontrolled migration and an increase in the number of adoptions conducted across international borders [7].

Congenital and acquired diseases such as DS can alter the indices concerning such assessment. DS individuals might present different clinical characteristics [27,28], such as delayed teeth eruption in both, deciduous and permanent dentitions, a condition that might also affect non-DS individuals [29,30].

Although under a common genetic control, the influence of individual, environmental, hormonal and ethnic factors lead to individual and population variability of exact chronology of these events, within normal variation patterns. This is the reason why biological/physiological age is never equal to chronological age and why the results are always associated with a mean error. It is thus much more correct to say age estimation instead of age determination $[8,15]$.

Many methods have been created for age estimation and the most popular one is the Greulich and Pyle Atlas, that uses hand and wrist exams [20]. Aiming to assess DA, Nolla method is one of the most commonly used in teaching and clinical practice [21]. While growing, the human body goes through a series of morphological changes - dental and osseous - involving a known chronological sequence that has been key to age estimation [8].

In this research, Table 3 shows DA always underestimated for both female and male individuals and DS and non-DS ones. This delay is more evident in DS than in non-DS individuals. Other authors also found underestimated DA in DS individuals [3,7] and other studies in non-DS individuals $[5,16,31,32]$. Just one author using Nolla method in non-DS individuals found DA overestimated [11] and others overestimated DA in non-DS individuals using Demirjian [33] method [2,10]. Regarding SA estimated using 
A

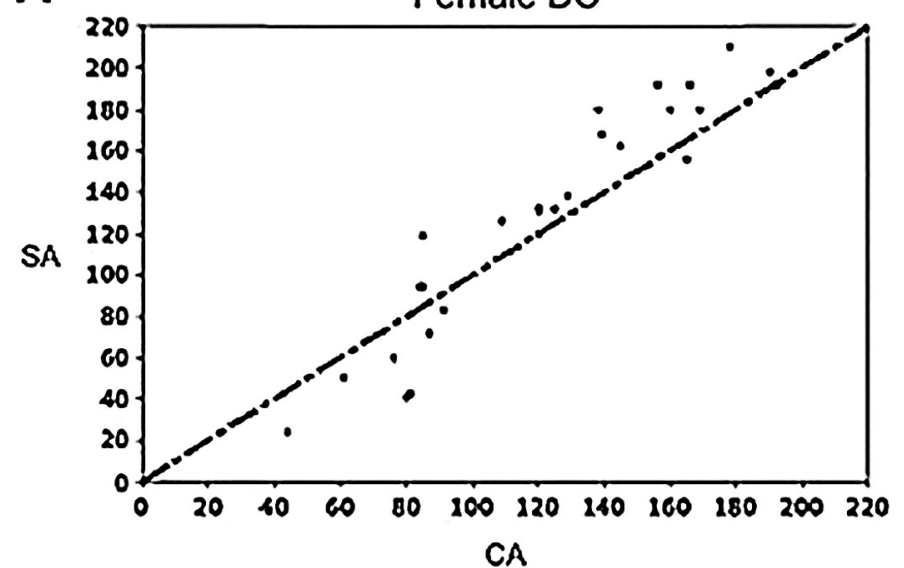

C

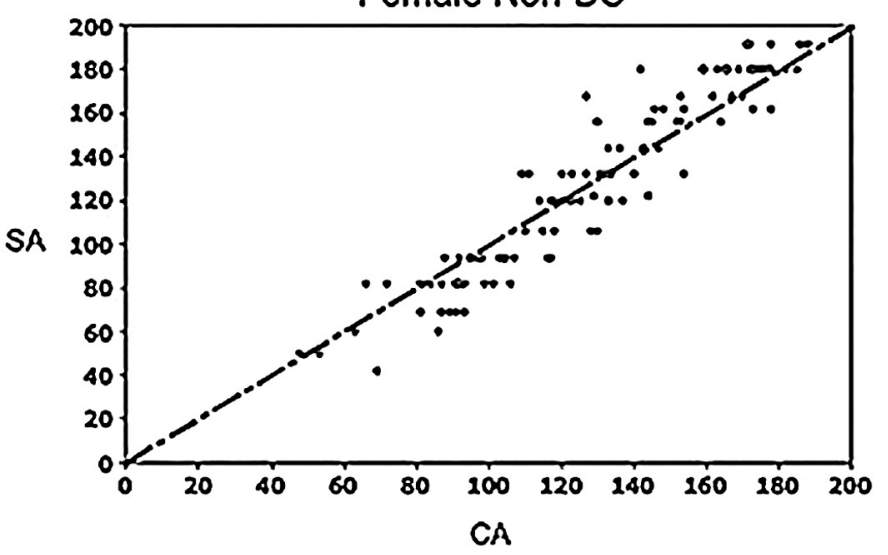

B

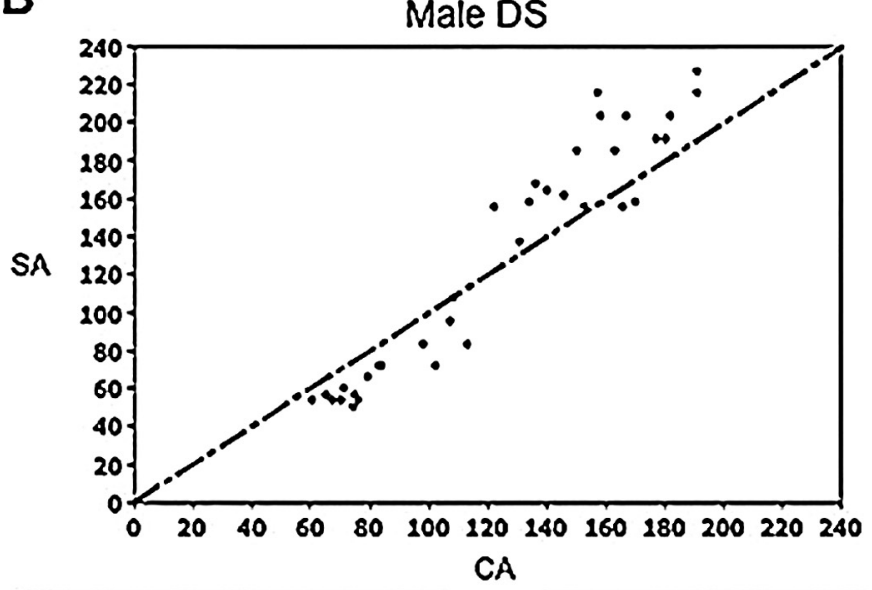

D

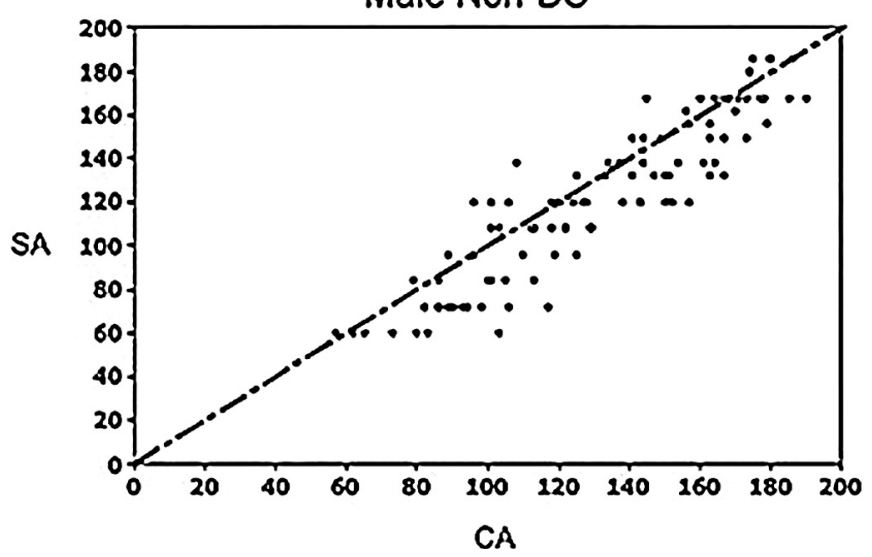

Fig. 6. Charts representing the difference between $S A \times C A$ each group.

Greulich and Pyle method, Table 3 shows it is overestimated for female and male individuals in DS group, similar for non-DS female and underestimated for non-DS male. Another study using Greulich and Pyle method in non-DS individuals agree with these results $[8,12,18]$.

Figs. 8-13 show the means for CA, DA and SA for each sub-group, G1, G2 and G3, for both, Control Group and the group of individuals with Down's syndrome, in all situations: Gathered Group (both

\section{Limits of Agreement (LA)}
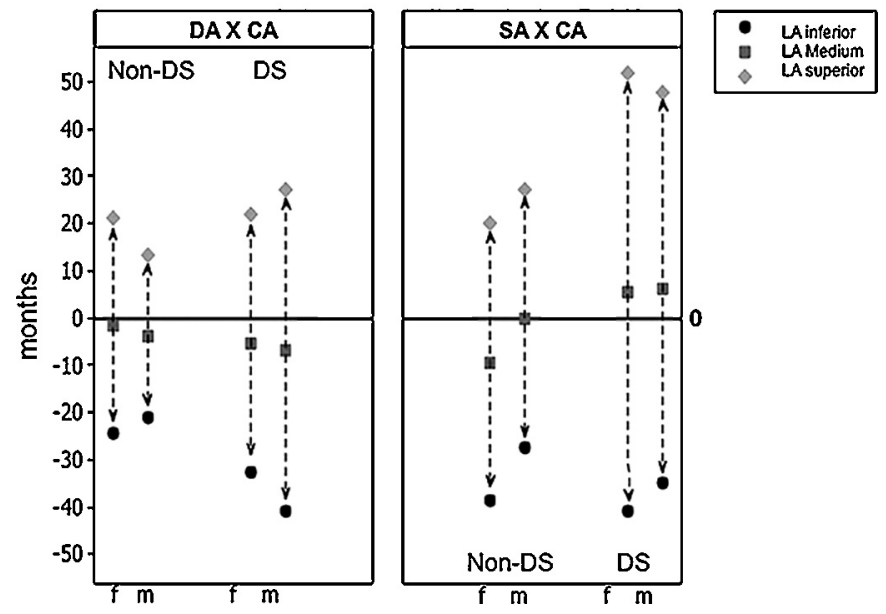

Fig. 7. Limits of concordance between DA and SA compared to CA, according to DS and non-DS individuals and gender. genders feminine and masculine), Feminine Group and Masculine Group. According to these figures, it can be observed that for all examined cases, DA has always been closer to CA.

For Control Group in the ANOVA test for comparison among CA, DA and SA, it was found that, in Gathered Group, Group 1 showed a statistically significant difference between CA and SA $(p<0.01)$; in Famine Group it was found statistically significant difference between CA and SA $(p<0.05)$ and DA and SA $(p<0.01)$ in Group 3; and in Masculine Group it was found statistically significant difference between CA and SA $(p<0.05)$ and DA and SA $(p<0.05)$ for Group 2. For the group with individuals with Down syndrome, in

Table 5

Linear correlation coefficient of Pearson and limits of concordance between $C A \times D A$ and $\mathrm{SA} \times \mathrm{CA}$ for DS and non-DS.

\begin{tabular}{llll}
\hline & $\begin{array}{l}\text { Limits of } \\
\text { concordance }\end{array}$ & $\begin{array}{l}\text { Coefficient of Pearson } \\
p \text {-valor }\end{array}$ & $\begin{array}{l}\text { Confidence } \\
\text { interval }(95 \%)\end{array}$ \\
\hline $\begin{array}{l}\text { Female } \\
\text { Non-DS }\end{array}$ & & & \\
CA $\times$ DA & $34.38 \mathrm{~m}$ & $0.967(p<0.05)$ & 2.13 to 5.36 \\
CA $\times$ SA & $54.52 \mathrm{~m}$ & $0.949(p<0.05)$ & -2.56 to 2.56 \\
With DS & & $0.927(p<0.05)$ & -13.58 to 0.17 \\
CA $\times$ DA & $68.15 \mathrm{~m}$ & $0.946(p<0.05)$ & -1.91 to 14.80 \\
CA $\times$ SA & $82.75 \mathrm{~m}$ & & -3.86 to 0.74 \\
Male & & $0.928(p<0.05)$ & 6.33 to 12.27 \\
Non-DS & & $0.928(p<0.05)$ & 0.61 to 10.13 \\
CA $\times$ DA & $45.44 \mathrm{~m}$ & $0.959(p<0.05)$ & -2.52 to 13.72 \\
CA $\times$ SA & $58.62 \mathrm{~m}$ & $0.928(p<0.05)$ & \\
With DS & & & \\
CA $\times$ DA & $54.34 \mathrm{~m}$ & & \\
CA $\times$ SA & $92.62 \mathrm{~m}$ & &
\end{tabular}


Table 6

Limits of concordance between $\mathrm{DA} \times \mathrm{CA}$ and $\mathrm{SA} \times \mathrm{CA}$, according to Bland-Altman method.

\begin{tabular}{|c|c|c|c|c|c|c|c|c|c|c|}
\hline & Total & $\%$ & Equal $(=)$ & $\%$ & Light $(<12)$ & $\%$ & Moderate $(>12 ;<24)$ & $\%$ & Remarkable (>24) & $\%$ \\
\hline \multicolumn{11}{|l|}{$\mathrm{DA} \times \mathrm{IC}$} \\
\hline Female DS & 116 & 100 & 10 & 8.62 & 84 & 72.41 & 21 & 18.10 & 1 & 0.86 \\
\hline Male DS & 27 & 100 & 4 & 14.81 & 9 & 33.33 & 11 & 40.74 & 3 & 11.11 \\
\hline Female non-DS & 100 & 100 & 3 & 3 & 64 & 64 & 31 & 31 & 2 & 2 \\
\hline Male non-DS & 35 & 100 & 1 & 2.85 & 19 & 54.28 & 11 & 31.42 & 4 & 11.42 \\
\hline \multicolumn{11}{|l|}{$\mathrm{SA} \times \mathrm{IC}$} \\
\hline Female DS & 116 & 100 & 3 & 2.58 & 66 & 56.89 & 41 & 35.34 & 6 & 5.17 \\
\hline Male DS & 27 & 100 & 2 & 1.72 & 9 & 33.33 & 8 & 29.63 & 8 & 29.63 \\
\hline Female non-DS & 100 & 100 & 4 & 4 & 43 & 43 & 39 & 39 & 14 & 14 \\
\hline Male non-DS & 35 & 100 & 1 & 2.85 & 19 & 25.71 & 13 & 37.14 & 12 & 34.28 \\
\hline
\end{tabular}

Table 7

Mean of CA, DA and SA for Gathered Group of the Control Group and the group of individuals with Down syndrome.

\begin{tabular}{llcc}
\hline & CA & DA & \multicolumn{1}{c}{ SA } \\
\hline Control & & & \\
G1 & 102.1143 & 97.8857 & 94.9714 \\
G2 & 140.7671 & 140.2192 & 138.3562 \\
G3 & 172.8302 & 165.5094 & 171.283 \\
Down syndrome & & & \\
G1 & 93.6 & 86.8 & 83.4667 \\
G2 & 144.4 & 141.6 & 168.4 \\
G3 & 192.5455 & 186 & 200.4545 \\
\hline
\end{tabular}

the ANOVA test for comparison among CA, DA and SA, in Gathered Group, it was found statistically significant difference between CA and SA $(p<0.01)$ and DA and SA $(p<0.01)$ for Group 2; in Feminine Group there was no difference between them in G1, G2 and G3; and in Masculine Group it was found statistically significant difference between CA and SA $(p<0.01)$ and DA and SA $(p<0.01)$ for Group 2. These data emphasize that DA was closer to $C A$.

Table 4 shows the relation between $\mathrm{CA} \times \mathrm{DA}$, emphasizing the DA is always lower than CA in both genders, in DS and non-DS groups, in most of the individuals. This fact can also be seen in Figs. 1 and 2, that shows scatter plots with the distribution of sample in each age.

It is difficult to compare our findings with other authors since the literature presents few reports focusing on $C A \times D A$ in DS individuals. One of them is the study of Diz et al. [7], who studied the correlation between DA and CA in patients with DS, cerebral palsy, and mental retardation using Nolla and Demirjian [33] methods. They did not found significant differences between DA and CA. In contrast, DA was significantly delayed compared with $\mathrm{CA}$ in girls with cerebral palsy or DS individuals. The difference

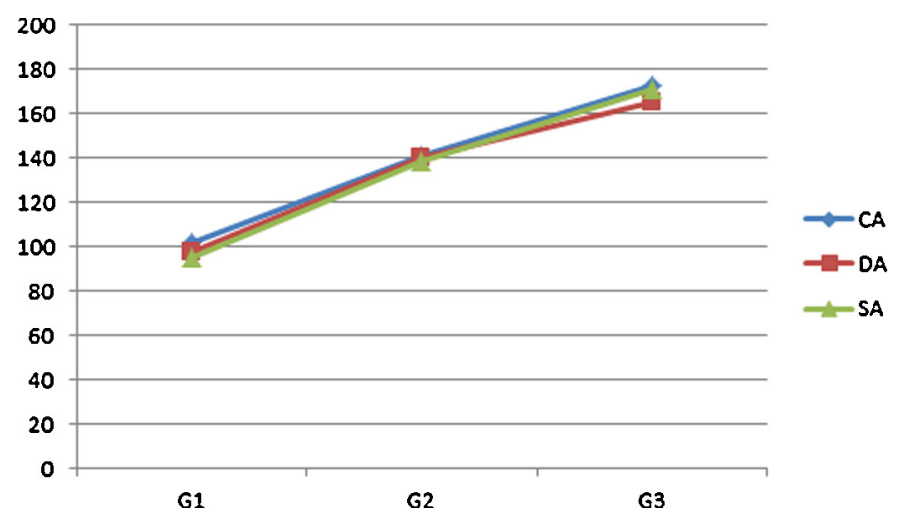

Fig. 8. Representative graph of CA, DA and SA means for Gathered Group of Control Group. between DA and CA was not significant between individuals with DS and non-DS. Moraes et al. [3] used Nolla method and observed that DA was lower than CA; however, this difference was only significant for females. The difference between $\mathrm{DA} \times \mathrm{CA}$ was not significant between individuals with DS and non-DS (both genders). They concluded that dental maturation in individuals with DS occurs similarly to non-DS individuals. Regarding DA $\times$ CA in non-DS individuals, Mohammed et al. [11] evaluated the accuracy of four DA estimation methods in southern Indian non-DS children and found that Nolla method was the most accurate in estimating DA. Miloglu et al. [32] evaluated whether or not Nolla method was appropriate for Turkish children DA determination and concluded that although the accuracy of this method was suitable for boys, it was not suitable for girls.

It is also possible to consider that SA was advanced when compared to CA in most of the individuals, except for non-DS males. When SA was considered to DS individuals using Greulich and Pyle method, Moraes et al. [24] showed that at the age of 7 years, SA of individuals with DS was delayed in relation to their $\mathrm{CA}(\mathrm{SA}<\mathrm{CA})$. On the other hand, at the age of 15 years, their SA was advanced in relation to their CA (SA $>C A)$. They suggested that DS individuals have a shorter period of adolescence development when compared to non-DS individuals. Santos et al. [8], compared Greulich and Pyle method with Maturos 4.0 program for age estimation on non-DS individuals and reported that the accuracy of

Table 8

Mean of CA, DA and SA for Feminine Group of the Control Group and the Group of individuals with Down syndrome.

\begin{tabular}{lllc}
\hline & CA & DA & SA \\
\hline Control & & & \\
G1 & 101.75 & 96.3 & 94.65 \\
G2 & 140.8605 & 140.093 & 144.4651 \\
G3 & 168 & 180.4286 \\
Down syndrome & & & \\
G1 & 92.25 & 79.5 & 87.5 \\
G2 & 141.7143 & 135.4286 & 165.4286 \\
G3 & 184.1 & 175.2 & 192 \\
\hline
\end{tabular}

Table 9

Mean of CA, DA and SA for Masculine Group of the Control Group and the group of individuals with Down syndrome.

\begin{tabular}{lllc}
\hline & CA & DA & SA \\
\hline Control & & & \\
G1 & 102.6 & 100 & 95.4 \\
G2 & 140.6333 & 140.4 & 129.6 \\
G3 & 172.3636 & 164.1818 & 163.9091 \\
Down syndrome & & & \\
G1 & 95.1429 & 95.1429 & 78.8571 \\
G2 & 146.75 & 147 & 171 \\
G3 & 199.5833 & 195 & 207.5 \\
\hline
\end{tabular}




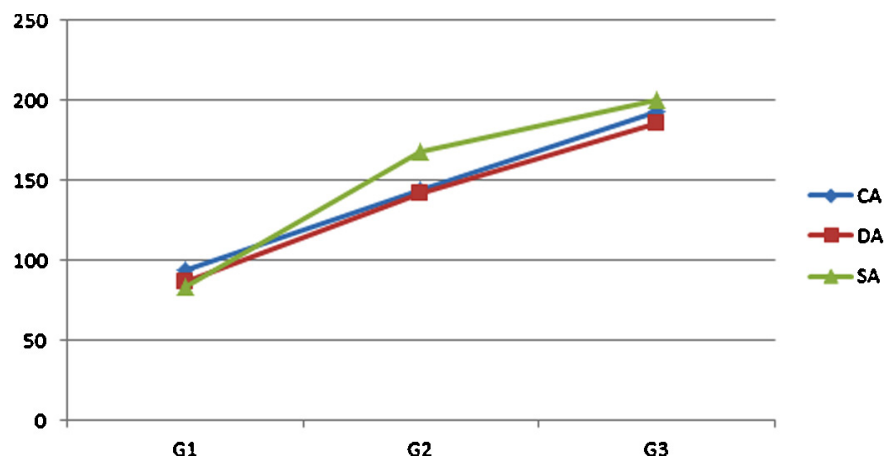

Fig. 9. Representative graph of CA, DA and SA means for Gathered Group of Individuals with Down syndrome.

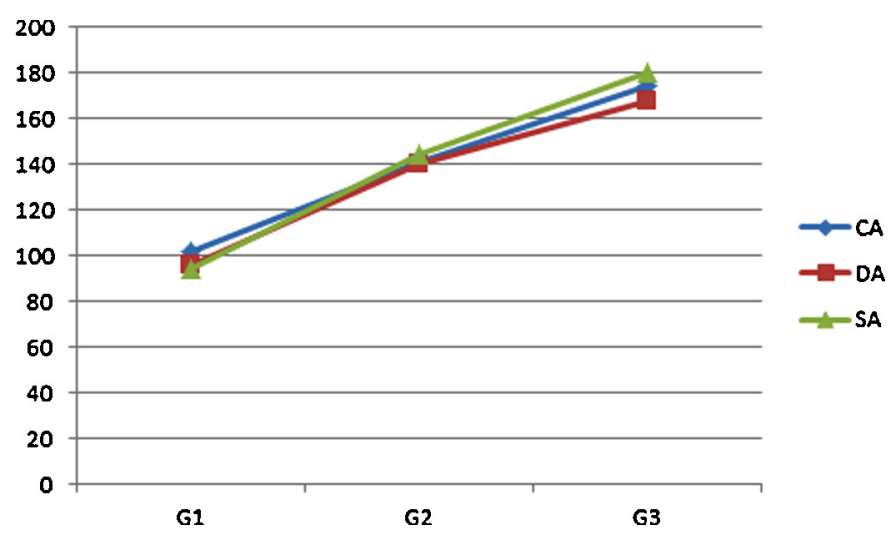

Fig. 10. Representative graph of CA, DA and SA means for Feminine Group of Control Group.

an age prediction method depends on age group. They concluded that the methods achieved different performances and that Greulich and Pyle method seems to be better than Maturos program [34]. In contrast, Patil [12] evaluated SA in Indian individuals and concluded that Greulich and Pyle method is not applicable for Indian children, especially in middle and late childhood, for both sexes.

Table 5 shows the linear correlation coefficient of Pearson used to verify the concordance between the methods. The limits of concordance between CA $\times$ DA for DS and non-DS individuals showed lower values than those for $\mathrm{SA} \times \mathrm{CA}$, suggesting that the results for DA have more concordance. This is also shown in Fig. 7, with the limits of concordance between DA and SA compared to CA, for DS and non-DS individuals, with a lower discordance observed between DA $\times$ CA and greater discordance in the DS group.

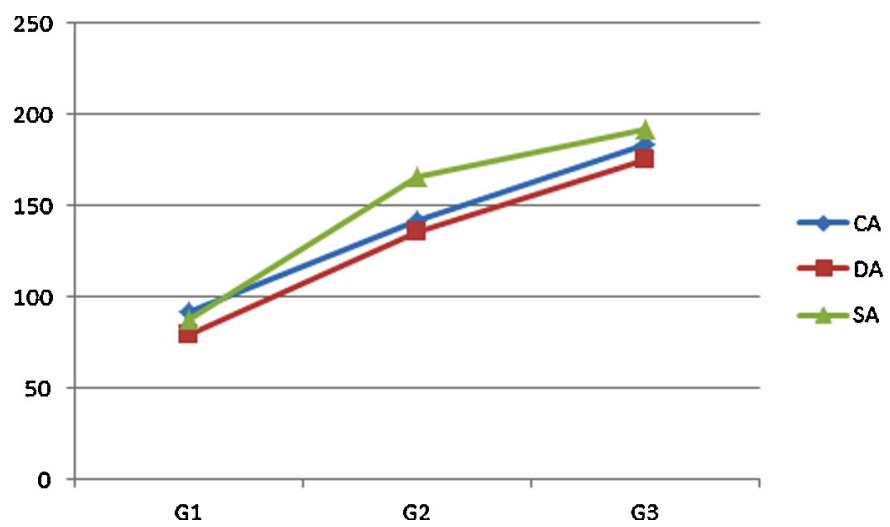

Fig. 11. Representative graph of CA, DA and SA means for Feminine Group of Individuals with Down syndrome.

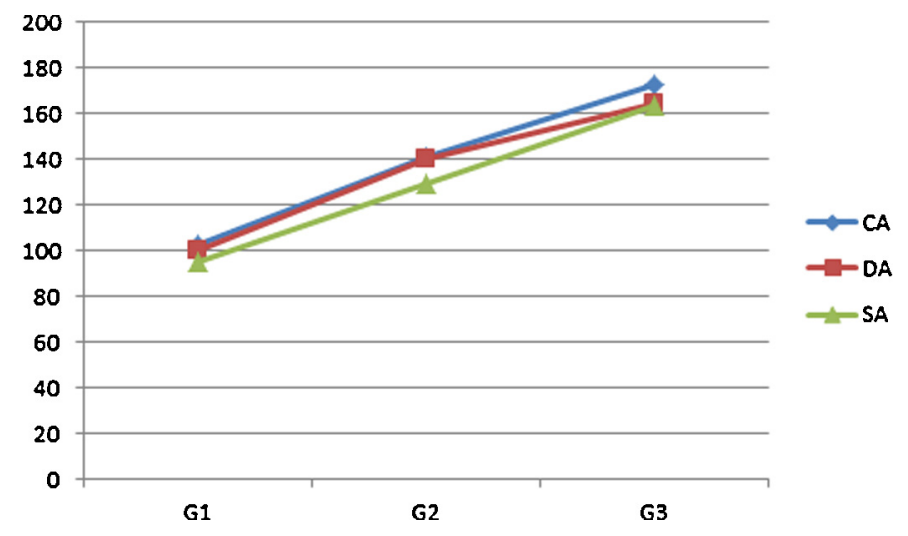

Fig. 12. Representative graph of CA, DA and SA means for Masculine Group of Control Group.

Several studies compared DA $\times$ CA and SA $\times$ CA using Demirjian and Greulich and Pyle methods in non-DS individuals. However, there are no studies using Nolla-Greulich and Pyle methods, neither with DS nor with non-DS individuals. Varkkola [35] estimated CA using dental (Demirjian method, dental eruption) and skeletal methods (Greulich and Pyle; Tanner and Whitehouse [36]) in nonDS individuals and concluded that dental methods are more accurate in childhood compared to skeletal methods, until the teeth have erupted and root development was complete, except for the wisdom teeth. In adolescence, however, the validity of skeletal methods improves considerably. Cameriere et al. [37,38], using the tooth and wrist-hand methods to estimate the CA of non-DS children, showed similar results when compared to skeletal and dental methods, with $83.6 \%$ for tooth and $83 \%$ for hand-wrist. On the other hand, Pechnikova [18], also in a study with non-DS individuals, showed that the lowest mean variance (CA) was shown by Greulich and Pyle method, followed by Demirjian method.

Table 6 shows limits of concordance between DA $\times$ CA and $\mathrm{SA} \times \mathrm{CA}$, according to Bland-Altman method, with numbers and percentages of individuals related to differences between $\mathrm{DA} \times \mathrm{CA}$ and $\mathrm{SA} \times \mathrm{CA}$, which were considered equal (without differences), light (differences less than 12 months), moderate (between 12 and 24 months), remarkable (greater than 24 months). DA presents, mostly, lower discordance than SA, regarding, mainly, DS individuals, who present remarkable differences.

Regarding differences between DS and non-DS, the accuracy between dental and skeletal methods in the present study showed that DS individuals presented much more variations than non-DS individuals for both genders. While DA showed light differences for non-DS (less than 12 months) with $72.41 \%$ for girls and $64 \%$ for

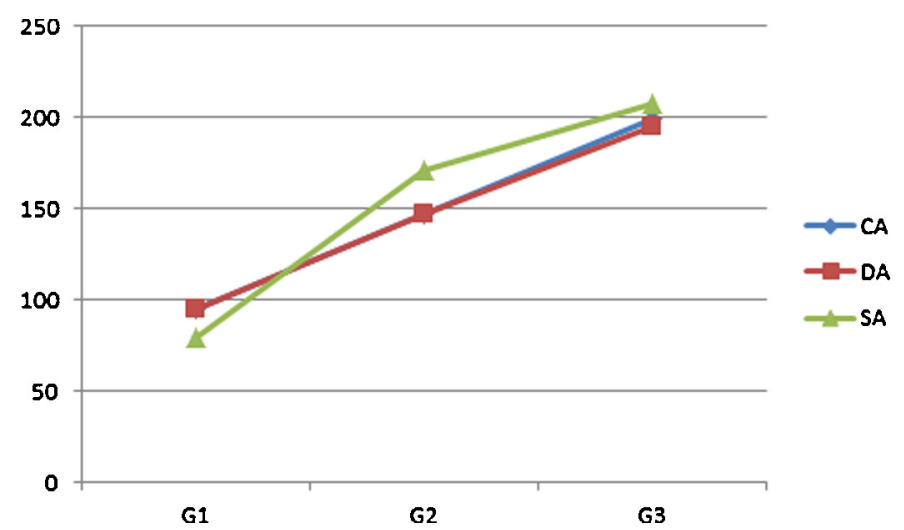

Fig. 13. Representative graph of CA, DA and SA means for Masculine Group of Individuals with Down syndrome. 
boys, for DS, it was found $33.33 \%$ for girls and $54.28 \%$ for boys and DS presented $11.11 \%$ for girls and $11.42 \%$ for boys with remarkable differences (greater than 24 months). Remarkable differences are noted in the relation $\mathrm{SA} \times \mathrm{CA}$, mainly in the DS group. Fig. 6 shows the highest range variance in SA, mainly in DS group.

The applicability of a method must be judged by its purpose or target population. Intervals lower than 6 months are considered satisfactory toward age estimation in cases of adoption, a condition for which our study was mainly intended [27,28,39-42]. Our study showed a higher percentage of the total individuals presenting lower differences than 12 months for DA when compared to SA, which means better accuracy of DA in relation to SA, for DS and non-DS individuals. Serinelli et al. [22] provided evidence that the ranges of age estimations derived from different studies are very wide for forensic purposes. They mentioned that the Tanner and Whitehouse method applied in Mongoloid males showed a range between 25.8 and 9.24 months.

Previous papers have shown the importance of combining dental and skeletal analyses for age estimation. The combination of SA and DA variables represented a significant improvement in the prediction of the CA of the subjects in the population, reducing the number of ethically unacceptable test errors to a minimum [20,43]. Serinelli et al. [22] confirmed the idea that the accuracy of age determination in living individuals should not be exclusively based on X-ray methods on the left hand-wrist. As already proposed by the International Study Group on Forensic Age Estimation [1] and applied $[1,44]$, the age estimation is likely to be more accurate when different procedures are integrated (physical examination, dental and skeletal methods) [14,20]. This idea should be taken into account, mainly, considering variations in DS individuals development. Considering the gap in the literature about age estimation in DS, as this study did, further studies are necessary to estimate CA of individuals with DS.

In summary, our results showed closer values and lower discordance between DA $\times$ CA than $\mathrm{SA} \times \mathrm{CA}$ for DS and non-DS individuals. On the basis of these evidences, it seems fair to suggest that DA, using Nolla method, is more accurate than SA, using Greulich and Pyle method. More caution is required for age estimation for DS individuals, since they present much more variation than non-DS individuals. However, none of the methods is absolutely precise in estimating CA for DS individuals. We believe that the combination of SA with DA variables could represent a significant improvement in the prediction of CA of DS individuals, reducing the possibility of mistakes.

\section{Conclusions}

1. DA estimated by Nolla method is underestimated for DS and non-DS individuals and it is more notable in DS individuals.

2. SA estimated by Greulich and Pyle method is overestimate, except for non-DS males.

3. The rate of variance is higher in SA than DA and in DS than nonDS individuals.

4. There is higher concordance between $\mathrm{DA} \times \mathrm{CA}$ than $\mathrm{SA} \times \mathrm{CA}$; i.e., DA estimated by Nolla method is more accurate than SA evaluated by Greulich and Pyle method for estimating CA for DS and non-DS individuals. However, none of the methods seems to be precise toward age estimation of DS individuals. More caution is required for age estimation in DS individuals.

\section{References}

[1] A. Schmeling, G. Geserick, W. Reisinger, A. Olze, Age estimation, Forensic Sci. Int 165 (2007) 178-181.

[2] A.M. Alshihri, E. Kruger, M. Tennant, Dental age assessment of 4-16 year old Western Saudi children and adolescents using Demirjian's method for forensic
Dentistry, Egypt. J. Forensic Sci. (2015), http://dx.doi.org/10.1016/ j.ejfs.2015.03.003.

[3] M.E.L. Moraes, L.C. Moraes, M. Cardoso, W. Ursi, S.L.P.C. Lopes, Age assessment based on dental calcification in individuals with Down syndrome, Res. Dev. Disabil. 34 (2013) 4274-4279.

[4] E. Cunha, E. Baccino, L. Martrille, F. Ramsthaler, J. Prieto, Y. Schuliar, N. Lynnerup, C. Cattaneo, The problem of aging human remains and living individuals: a review, Forensic Sci. Int. 193 (2009) 1-13.

[5] L.M. Kurita, A.V. Menezes, M.S. Casanova, F. Haiter-Neto, Dental maturity as an indicator of chronological age: radiographic assessment of dental age in a Brazilian population, J. Appl. Oral Sci. 15 (2007) 99-104.

[6] M.E.L. Moraes, L.C. Moraes, G.N. Dotto, P.P. Dotto, L.R.A. Santos, Dental anomalies in patients with Down syndrome, Braz. Dent. J. 18 (2007) 346-350.

[7] P. Diz, J. Limeres, A.F.P. Salgado, I. Tomás, L.F. Delgado, E. Vázquez, J.F. Feijoo, Correlation between dental maturation and chronological age in patients with cerebral palsy, mental retardation, and Down syndrome, Res. Dev. Disabil. 32 (2011) 808-817.

[8] C. Santos, M. Ferreira, F.C. Alves, E. Cunha, Comparative study of Greulich and Pyle Atlas and Maturos 4.0 program of age estimation in a Portuguese sample, Forensic Sci. Int. 212 (2011) 276.e1-276.e7.

[9] A. Schmeling, C. Grundmann, A. Fuhrmann, H.-J. Kaatsch, B. Knell, F. Ramsthaler, W. Reisinger, T. Riepert, S. Ritz-Timme, F.W. Rösing, K. Rötzscher, G. Geserick, Criteria for age estimation in living individuals, Int. J. Legal Med. 122 (2008) 457-460.

[10] N. Akkaya, H.O. Yilanci, D. Goksuluk, Applicability of Demirjian's Methods and Willems Method for Age Estimation in a Sample of Turkish Children, 2015.

[11] R.B. Mohammed, P. Sanghvi, K.K. Perumalla, D. Srinivasaraju, J. Srinivas, U.S. Kalyan, M.D. Iftekhar Rasool, Accuracy of four dental age estimation methods in southern Indian children, J. Clin. Diagn. Res. 9 (1) (2015) HC01-HC08.

[12] S.T. Patil, M.P. Parchand, M.M. Meshram, N.Y. Kamdi, Applicability of Greulich and Pyle skeletal age standards to Indian children, Forensic Sci. Int. 216 (2012) 200.e1-200.e4.

[13] D. Gibelli, D. De Angelis, C. Cattaneo, Radiological pitfalls of age estimation in adopted children: a case report, Minerva Pediatr. 2 (2015) 203-208.

[14] V. Santoro, A. de Donno, M. Marrone, C.P. Campobasso, F. Introna, Forensic age estimation on living individuals: a retrospective analysis, Forensic Sci. Int. 193 (2009) 129.e1-129.e4

[15] G.P. Beunen, A.D. Rogol, R.M. Malina, Indicators of biological maturation and secular changes in biological maturation, Food Nutr. Bull. 27 (2006) 244-256.

[16] M. Maber, H.M. Liversidge, M.P. Hector, Accuracy of age estimation of radiographic methods using developing teeth, Forensic Sci. Int. 159 (2006) 68-73.

[17] B. Nur, A. Kusgoz, M. Bayram, M. Celikoglu, M. Nur, S. Kayipmaz, S. Yildirim, Validity of Demirjian and Nolla methods for dental age estimation for Northeastern Turkish children aged 5-16 years old, Med. Oral Patol. Oral Cir. Bucal 17 (2012) e871-e877.

[18] M. Pechnikova, D. Gibelli, D. De Angelis, F. De Santis, C. Cattaneo, The "blind age assessment": applicability of Greulich and Pyle, Demirjian and Mincer aging methods to a population of unknown ethnic origin, Radiol. Med. 116 (2011) 1105-1114.

[19] Z. Kırzıoğlu, D. Ceyhan, Accuracy of different dental age estimation methods on Turkish children, Forensic Sci. Int. 216 (2012) 61-67.

[20] V. Santoro, R. Roca, A. De Donno, C. Fiandaca, G. Pinto, S. Tafuri, F. Introna, Applicability of Greulich and Pyle and Demirjan aging methods to a sample of Italian population, Forensic Sci. Int. 221 (2012) 153.e1-153.e5.

[21] M.V. Bolanos, M.C. Marinque, M.J. Bolanos, M.T. Briones, Approaches to chronological age assessment based on dental calcification, Forensic Sci. Int. 110 (2000) 97-106.

[22] S. Serinelli, V. Panetta, P. Pasqualetti, D. Marchetti, Accuracy of three age determination X-ray methods on the left hand-wrist: a systematic review and metaanalysis, Legal Med. 13 (2011) 120-133.

[23] M.E.L. Moraes, M.S. Bastos, L.R. Santos, J.C. Castilho, L.C. Moraes, E. Medici Filho, Dental age in patients with Down syndrome, Braz. Oral Res. 21 (2007) 259-264.

[24] M.E.L. Moraes, J.L.O. Tanaka, L.C. Moraes, E. Medici-Filho, J.C. Castilho, Skeletal age of individuals with Down syndrome, Spec. Care Dent. 28 (2008) 101-106.

[25] C.M. Nolla, The development of the permanent teeth, J. Dent. Child. 27 (1960) 254-266.

[26] W.W. Greulich, S.I. Pyle, Radiographic Atlas of Skeletal Development of the Hand and Wrist, Stanford University Press, Stanford, UK, 1959.

[27] S. Suri, B.D. Thompson, L. Cornfoot, Cranial base, maxillary and mandibular morphology in Down syndrome, Angle Orthod. 80 (2010) 861-869.

[28] S. Shore, T. Lightfoot, P. Ansell, Oral disease in children with Down syndrome: causes and prevention, Community Pract. 83 (2010) 18-21.

[29] G. Orner, Eruption of permanent teeth in mongoloid children and their sibs, J. Dent. Res. 52 (1973) 1202-1208.

[30] L. Jara, A. Ondarza, R. Blanco, C. Valenzuela, The sequence of eruption of the permanent dentition in a Chile an sample with Down's syndrome, Arch. Oral Biol. 38 (1993) 85-89.

[31] L.F. Tomás, L.S.M. Mónico, I. Tomás, P. Varela-Patino, B. Martin-Biedma, The accuracy of estimation chronological age from Demirjian and Nolla methods in a Portuguese and Spanish sample, BMC Oral Health 14 (2014) 160.

[32] O. Miloglu, M. Celikoglu, A. Dane, K. Cantekin, A.B. Yilmaz, Is the assessment of dental age by the Nolla method valid for eastern Turkish children? J. Forensic Sci. 56 (2011) 1025-1028.

[33] A. Demirjian, H. Goldstein, J.M. Tanner, A new system of dental age assessment, Hum. Biol. 45 (1973) 211-227.

[34] M.-M. Sempé, Lànalyse da maturation squelettique: la pédiatrie au quotidian, Les Edition INSERM, Paris, 1987 
[35] O. Varkkola, H. Ranta, M. Metsaniity, A. Sajantila, Age assessment by the Greulich and Pyle method compared to other skeletal X-ray and dental methods in data from Finnish child victims of the Southeast Asian Tsunami, Forensic Sci. Med. Pathol. 7 (2011) 311-316.

[36] J.M. Tanner, R.M. Whitehouse, W.A. Marshall, M.J.R. Healy, H. Glodstein, Assessment of Skeletal Maturity and Prediction of Adult Height (TW2 Method), Academic Press, London, England, 1975.

[37] R. Cameriere, L. Ferrante, M. Cingolani, Age estimation in children by measurement of open apices in teeth, Int. J. Legal Med. 120 (2006) 49-52.

[38] R. Cameriere, L. Ferrante, D. Mirtella, M. Cingolani, Carpals and epiphyses of radius and ulna as age indicators, Int. J. Legal Med. 120 (2006) 143-146.

[39] F.T. Oliveira, A.L. Capelozza, J.R. Lauris, I.R. de Bullen, Mineralization of mandibular third molars can estimate chronological age-Brazilian indices, Forensic Sci. Int. 219 (2012) 147-150.
[40] G.A. Sartorius, E. Nieschiag, Paternal age and reproduction, Hum. Reprod. Update 16 (2010) 65-79.

[41] M. Abou El-Yazeed, W. Abou Zeid, W. Tawfik, Dental maturation assessment by Nolla's technique on a group of Egyptian children, Aust. J. Basic Appl. Sci. 2 (4) (2008) 1418-1424.

[42] J. Alió, J. Lorenzo, M.C. Iglesias, F.J. Manso, E.M. Ramírez, Longitudinal maxillary growth in Down syndrome patients, Angle Orthod. 81 (2011) 253-259.

[43] P.M. Garamendi, M.I. Landa, J. Ballesteross, M.A. Solano, Reliability of the methods applied to assess age minority in living subjects around 18 years old. A survey on a Moroccan origin population, Forensic Sci. Int. 154 (2005) 3-12.

[44] S. Schmidt, B. Kock, R. Schulz, W. Reisinger, A. Schmeling, Studies in use of the Greulich-Pyle skeletal age method to assess criminal liability, Legal Med. 10 (2008) 190-195. 